\title{
Defining Nursing Informatics: A Narrative Review
}

\author{
Lisa REID ${ }^{\mathrm{a}, \mathrm{b}, 1}$, Anthony MAEDER ${ }^{\mathrm{a}, \mathrm{b}}$, Didy BUTTON ${ }^{\mathrm{a}}$, \\ Katrina BREADEN ${ }^{\mathrm{a}}$ and Mark BROMMEYER ${ }^{\mathrm{c}}$ \\ ${ }^{\mathrm{a}}$ College of Nursing and Health Sciences, \\ Flinders University, Adelaide, South Australia \\ ${ }^{\mathrm{b}}$ Flinders Digital Health Research Centre, \\ Flinders University, Adelaide, South Australia \\ ${ }^{\mathrm{c}}$ College of Business, Government and Law, \\ Flinders University, Adelaide, South Australia
}

\begin{abstract}
Healthcare has experienced rapid transformation with the development of digital technologies which aim to make healthcare safer and more efficient. In response, health informatics has evolved, including nursing informatics, which integrates nursing, information and communication technologies (ICT) and professional knowledge to improve patient outcomes. New language has developed to describe informatics and its processes; however, this has generally been poorly understood. This paper will describe current definitions of nursing informatics from three different healthcare contexts: Australia, the United States of America and Canada, to identify the similarities and differences between these definitions and to summarise the distinct bodies of knowledge described by each country. These countries have amongst the oldest definition attempts in the literature. A pragmatic approach was taken in this narrative review, working forward from historic references and backwards from recent references extracted from published health and nursing informatics literature.
\end{abstract}

Keywords. Informatics, nursing, definition

\section{Introduction}

Global healthcare is in transition with digital technologies aiming to improve safety, efficiency and accessibility of healthcare. In Australia, digital health has experienced rapid investment in infrastructure and infostructure; including My Health Record, clinical information systems, and GP practice software [1]. As the largest healthcare workforce [2], nurses play a pivotal role in digital health [3], and need to embrace ICT to effectively function within the contemporary healthcare environment [4]. However, barriers to the use of these technologies including poor computer literacy [5], limited workplace education and support [6], limited informatics' opportunities for undergraduate nursing students [7] and confusion about what nursing informatics is and what it means to nursing [8].

${ }^{1}$ Corresponding Author, Lisa Reid, College of Nursing and Health Sciences, Flinders University, GPO Box 2100, Adelaide, South Australia 5001. 
Despite the slow transformation from paper-based to digital data, the way in which healthcare is delivered is changing [1]. As digital technologies have developed, the terminologies used to describe these concepts have often been poorly understood, with "an expanding cloud of chaos" surrounding the word informatics [9]. This lack of a consistent taxonomy has resulted in a call for a consensus on definitions within health informatics [10]; with nursing informatics also struggling to define its body of knowledge with "at least 14 definitions of nursing informatics" emerging over the past four decades [11]. A narrative review process has been undertaken, as detailed by Baumeister and Leary [12] and Ferrari [13], to identify current definitions of nursing informatics in Australia, the United States of America and Canada and to summarise the distinct bodies of knowledge from each country.

\section{Methods}

A pragmatic approach was used in this narrative review, working forward from historic definitions and retrospectively from recent definitions in published health and nursing informatics literature. Narrative reviews describe published articles to inform debate, appraise research and identify gaps in current knowledge. This review, undertaken as part of a PhD thesis, sought to identify current definitions of nursing informatics, adding to the body of knowledge on nursing informatics. A literature search was conducted for definitions of nursing informatics. Using the snowball technique [14] additional publications were obtained from the reference lists of retrieved articles. Following searches, the results were screened. The screening process determined whether each article met the inclusion criteria of providing a definition of nursing informatics, relevant to the contexts of Australia, the United States or Canada.

\section{Results}

Current definitions of nursing informatics have been informed by the work of nursing informatics' pioneers, including Hannah [15], Graves and Corcoran [16], and Saba and McCormick [17]. In their seminal work on the evolution of nursing informatics definitions, Staggers and Thompson [18] identified information technology-oriented, conceptually oriented and role-oriented definitions. From Scholes and Barber's [18] early definition of nursing informatics as "the application of computer technology to all fields of nursing - nursing service, nurse education, and nursing research", to Nelson and Joos [19] recommendation to include the concept of wisdom to this definition, and QSEN Institute's (Quality and Safety Education for Nurses) definition of nurses needing to "use information and technology to communicate, manage knowledge, mitigate error, and support decision making" [20]; the discussion of nursing informatics has moved away from a technology focus and towards defining nurses' use of technology [21].

\subsection{Current Definitions of Nursing Informatics}

Today, the International Medical Informatics Association (IMIA) [22] states that "Nursing Informatics science and practice integrates nursing, its information and knowledge and their management with information and communication technologies to 
promote the health of people, families and communities world wide". The definitions of nursing informatics from Australia, the United States and Canada will now be discussed.

\subsection{Australia}

Nursing informatics began in Australia around 1984. The Nursing in Computer Group Victoria formed in 1985, joining with other states as part of the Australian Nursing Informatics Council in 1994 [23]. This group became known as Nursing Informatics Australia (NIA), a special interest group of the Health Informatics Society of Australia (HISA) [24]. The subsequent amalgamation of HISA and the Australasian College of Health Informatics (ACHI), resulted in the formation of the Australasian Institute of Digital Health (AIDH), and the Nursing. Midwifery community of practice was created.

In 2004, A Framework for Nursing Informatics in Australia [25] cited Staggers and Thompson's definition of nursing informatics (stating in part) "the specialty that integrates nursing science with multiple information and analytical sciences to identify, define, manage, and communicate data, information, knowledge, and wisdom in nursing practice" This definition has remained unchanged and was cited in the Nursing Informatics Position Statement, published in 2017 by the Australian College of Nursing (ACN), HISA and NIA [26]. The Australian Nursing and Midwifery Accreditation Council (ANMAC) [27], the accreditation authority for nursing and midwifery education in Australia, adapted Graves and Corcoran's [16] earlier definition to define nursing informatics as the "knowledge and skills required by the registered nurse to integrate nursing science, computer science, and information science to manage and communicate data, information and knowledge in nursing practice".

\subsection{United States of America}

In the United States, the first workshop on computer technologies and nursing was held in 1973 [17]. In 1992, the American Nurses Association (ANA) Council of Computer Applications in Nursing defined nursing informatics as "A specialty that integrates nursing science, computer science, and information science in identifying, collecting, processing, and managing data and information to support nursing practice, administration, education, and research and to expand nursing knowledge" [18]. In 2008, the American Nurses Association [28] adopted the Data-Information-KnowledgeWisdom (DIKW) framework, defining informatics as "the specialty that integrates nursing science with multiple information and analytical sciences to identify, define, manage and communicate data, information, knowledge and wisdom in nursing practice" This definition has remained unchanged since this time, with the most recent Nursing Informatics: Scope and Standards of Practice supporting the definition [29]. The ANA definition was adopted by the Technology Informatics Guiding Education Reform (TIGER) Initiative during the development of recommendations for education reform [30] and the American Nursing Informatics Association (ANIA) developed a similar definition. In contrast, the American Medical Informatics Association (AMIA) - Nursing Informatics Working Group endorsed the IMIA's definition of nursing informatics [31] to reflect the application of knowledge in dealing with nursing practice and addressing the relationship between nursing practice and ICT. 


\subsection{Canada}

The Canadian Organization for the Advancement of Computers in Health (COACH) Nursing Special Interest Group was established in 1987 and following the disbanding of the group in 2002, the Canadian Nursing Informatics Association (CNIA) was established [32]. In 1985, Hannah [15] asserted that "any use of information technology by nurses in relation to the care of patients, or the educational preparation of individuals to practice in the discipline is considered nursing informatics." Since this time, the CNIA has sought to address nursing informatics expertise and informatics competencies and released a joint statement with the Canadian Nurses Association (CNA) endorsing the IMIA's definition [33]. The Canadian Association of Schools of Nursing (CASN) [34] has also endorsed the IMIA definition.

\section{Discussion}

In 2002, Staggers and Thompson stated that "a definition for nursing informatics guides role delineation for nurses interested in informatics and suggests directions for practice, education, training, and research" [18]. However, since this time, limited consensus has been reached on an operational definition for nursing informatics and its associated areas of practice $[11 ; 35]$ Consequently, there remains confusion amongst nurses as to what nursing informatics is, and how it impacts on their practice [8]. This confusion is worsened by the multiple definitions of nursing informatics. Therefore, developing a global definition of nursing informatics is required, so that nurses can be informed about this essential aspect of nursing care in the 21 st century.

\section{Conclusions}

This paper has described current definitions of nursing informatics in Australia, the United States and Canada. These definitions have evolved and changed over time, and currently there remain several definitions in use. The similarities include the endorsement of the IMIA definition of nursing informatics by some professional bodies in the USA and Canada, and the integration of nursing and technology. The differences, whilst nuanced, may be linked to the number of organisations in each country, which represent the interests of nursing informatics, thereby resulting in siloed bodies of knowledge. If the purpose of nursing informatics is to improve the safety and quality of patient care, then as a profession, nurses need to be provided with a clearer understanding of nursing informatics. This will only benefit nursing by leading to a consolidated body of knowledge, a clear education mandate and a digital ready workforce.

\section{References}

[1] Health Informatics Society of Australia (HISA). Leadership in clinical informatics: a HISA White Paper. In, 2018.

[2] Australian Institute of Health and Welfare (AIHW). Australia's health 2016. In: Australian Institute of Health and Welfare (AIHW), ed., Australian Government, Canberra, ACT, 2016.

[3] Australian Nursing and Midwifery Federation (ANMF). Digital Health: ANMF policy. In, 2018. 
[4] Chang J, Poynton MA, Gassert CR, Staggers N. Nursing informatics competencies required of nurses in Taiwan. International Journal of Medical Informatics 80 (2011), 332-340.

[5] Moule P, Ward R, Lockyer L. Nursing and healthcare students' experiences and use of e-learning in higher education. Journal of Advanced Nursing 66 (2010), 2785-2795.

[6] Kleib M, Nagle L. Factors associated with Canadian Nurses' Informatics competency. CIN: Computers, Informatics, Nursing 36 (2018), 406-415.

[7] Borycki EM, Foster J. A comparison of Australian and Canadian informatics competencies for undergraduate nurses. In: Nursing Informatics 2014, K. Saranto, C.A. Weaver, and P. Chang, eds., IOS Press Ebooks, Amsterdam, Netherlands, 2014, pp. 249-355.

[8] Dixon BE, Newlon CM. How do future nursing educators perceive informatics? Advancing the nursing informatics agenda through dialogue. Journal of Professional Nursing 26 (2010), 82-89.

[9] Friedman cp. What informatics is and isn't. JAMIA 20 (2012), 224-226.

[10] Hersh W. A stimulus to define informatics and health information technology. BMC Medical Informatics and Decision Making 9 (2009), 24.

[11] Hussey PA, Kennedy MA. Instantiating informatics in nursing practice for integrated patient centred holistic models of care: A discussion paper. Journal of Advanced Nursing 72 (2016), 1030-1041.

[12] Baumeister R, Leary M. Writing narrative literature reviews. Review of General Psychology 1 (1997), 311-320.

[13] Ferrari R., Writing narrative style literature reviews. Medical Writing 24 (2015), 230-235.

[14] Vázquez-Calatayud M, Errasti-Ibarrondo B, Choperena A. Nurses' continuing professional development: A systematic literature review. Nurse Educ Pract 50 (2021), 102963-102963.

[15] Hannah KJ. Nursing uses of computers and information science: Proceedings of the IFIP-IMIA International Symposium on Nursing Uses of Computers and Information Science. Calgary, Alberta, Canada, 1-3 May 1985, in: The IFIP-Imia International Symposium on Nursing Uses of Computers and Information Science, K.J. Hannah, E.J. Guillemin, and D.N. Conklin, eds., Elsevier Science Inc., Calgary, 1985, pp. 181-187.

[16] Graves JR, Corcoran S. The study of nursing informatics. Journal of Nursing Scholarship 21 (1989), $227-$ 231.

[17] Saba VK. Nursing informatics: yesterday, today and tomorrow. International Nursing Review 48 (2001), 177-187.

[18] Staggers N, Thompson CB. The evolution of definitions for nursing informatics: A critical analysis and revised definition. J Am Med Inform Assoc 9 (2002), 255-261.

[19] Nelson R, Joos I. On language in nursing: From data to wisdom. PLN Vision 1 (1989), 6.

[20] QSEN Institute (Quality and Safety in Nursing). Graduate QSEN competencies. In, 2020.

[21] Ronquillo MC, Currie ML, Rodney MP. The evolution of data-information-knowledge-wisdom in nursing informatics. Advances in Nursing Science 39 (2016), E1-E18.

[22] International Medical Informatics Association - Nursing Informatics. IMIA Nursing Informatics (IMIA NI) Education Working Group. In: International Medical Informatics Association, IMIA, 2019.

[23] Hovenga EJ. Nursing informatics in Australia. M.D. Computing: computers in medical practice 14 (1997), 119-125.

[24] Health Informatics Society of Australia (HISA), Hovenga EJ, Kidd MR HISA. About our history - vision, collaboration, leadership. In, 2018.

[25] Conrick M, Hovenga EJ, Cook R, Laracuente T, Morgan T. A framework for nursing informatics in Australia. In, 2004.

[26] Australian College of Nursing (ACN), Health Informatics Society of Australia (HISA), Nursing Informatics Australia (NIA). Nursing Informatics Position Statement, In, 2017.

[27] Australian Nursing and Midwifery Accreditation Council (ANMAC). Health informatics and health technology - an explanatory note. In, 2014.

[28] American Nurses Association (ANA). Nursing informatics: scope and standards of practice., 2008.

[29] American Nurses Association (ANA). Nursing informatics: scope and standards of practice. In: ANA Standards of Nursing Informatics Practice, Nursebooks, Silver Spring, Maryland, 2015.

[30] Technology Informatics Guiding Educational Reform (TIGER). TIGER Informatics Competencies Collaborative (TICC): Final report. In, 2009.

[31] A.M.I.A.-N.I.W. Group. Nursing Informatics Working Group. In, 2019.

[32] Canandian Nursing Informatics Association (CNIA). History. In, n.d.

[33] Canadian Nurses Association (CNA), Canadian Nursing Informatics Association (CNIA). Nursing informatics: Joint position statement. In, 2017.

[34] Canadian Association of Schools of Nursing (CASN). Nursing informatics entry-to-practice competencies for registered nurses. In, 2015.

[35] Chauvette A, Paul P. History of nursing informatics in Canada. Canadian Journal of Nursing Informatics 11 (2016). 